\title{
Giant Pericardial Cyst: A Case Report and Review of Literature
}

\author{
Manouchehr Hekmat, ${ }^{1}$ Hamid Ghaderi, ${ }^{1}$ Hassan Tatari, ${ }^{1}$ Abbas Arjmand Shabestari, ${ }^{2}$ and \\ Seyedeh Adeleh Mirjafari, \\ ${ }_{1}^{1}$ Department of Cardiovascular Surgery, Shahid Modarres Hospital, Shahid Beheshti University of Medical Sciences, Tehran, Iran \\ ${ }^{2}$ Department of Radiology, Shahid Modarres Hospital, Shahid Beheshti University of Medical Sciences, Tehran, Iran \\ 3 Brain and Spinal Injury Research Center, Tehran University of Medical Sciences, Tehran, Iran \\ ${ }^{*}$ Corresponding author: Seyedeh Adeleh Mirjafari, Brain and Spinal Injury Research Center, Tehran University of Medical Sciences, Tehran, Iran. Tel: +98-2166581561, Fax: +98-2166938885, \\ E-mail:adeleh_60@yahoo.com
}

Received: July 10, 2014; Revised: September 14, 2014; Accepted: September 18, 2014

\begin{abstract}
Pericardial cysts are rare lesions. These benign anomalies are located in the middle mediastinum. In this article, we present a 24-year-old man who was referred to the emergency department with dyspnea and persistent cough. In physical exam, no abnormality was found. His past medical history was normal. His trans-thoracic echocardiogram showed an echo-lucent space next to the right atrium at the right cardiophrenic angle. No pericardial effusion was found. The patient underwent surgery. After midsternotomy, a huge cyst measuring approximately $13 \times 8 \times 5 \mathrm{~cm}$ in diameters was found on the right side and outside the pericardium that was totally excised. After 5 days, the patient was discharged and pathologic report confirmed preoperative diagnosis of pericardial cyst. Giant pericardial cysts are not common and in this report, we will review published case reports.
\end{abstract}

Keywords: Cardiac Surgery; Pericardial Cyst; Mediastinal Cyst

\section{Introduction}

Pericardial cysts are rare. These uncommon benign congenital anomalies are located in the middle mediastinum. The estimated incidence is $1: 100,000$. Their diameter is usually from $1-5 \mathrm{~cm}$ (1). These benign cysts are located at the right cardiophrenic angle in $70 \%$ of cases, left cardiophrenic angle in $22 \%$ of cases and rarely in the posterior or anterior superior part of the mediastinum in $8 \%$ of cases (2). Most of pericardial cysts (>50\%) are asymptomatic $(1,3)$ and have a benign natural course. Some cysts have symptoms such as dyspnea, chest pain, or persistent cough. Hemoptysis, fever, and pneumothorax (3) are unusual presentations. Although it occasionally presents with symptoms related to compression of adjacent structures, pericardial cysts usually have no symptoms and are almost always diagnosed incidentally.

In this case report, we describe a patient with a pericardial cyst. Presentation and the course of illness were unusual and the cyst was one of the largest cysts that has been reported to date. Pericardial cysts are not common and giant pericardial cysts are rare and only data of 12 cases were available from 2000 to 2014 in PubMed, and we will review available published articles in the literature. With improvement of technology and CT scan we are able to diagnose this benign congenital anomaly before surgery.

\section{Case Presentation}

A 24-year-old man presented to the emergency department with dyspnea and persistent cough. In physical exam, no abnormality was found. His past medical history was normal. Such an episode occasionally presented in the past year. There was no recent weight loss, cough, sputum production, exposure to tuberculosis, joint pain, or rash. The electrocardiogram (ECG) was normal.

Chest X-ray showed a large opacity obscuring the right heart border (Figure 1). His trans-thoracic echocardiogram showed an echo-lucent space next to the right atrium at the right cardiophrenic angle. His echocardiogram was normal, and no pericardial effusion was found. The apical four-chamber view of the transthoracic echocardiogram showed an echolucent space next to the right atrium at the right cardiophrenic angle, consistent with a pericardial cyst. The right and left ventricular chamber size and function were normal, and there was no valvular heart disease

Then computed tomography (CT) was recommended. CT revealed no pleural effusions, and a large fluid collection at the right pericardial border (Figure 2).

Extensive work-up for infectious and inflammatory causes, including blood cultures, viral antibodies, sputum acid fast bacilli's (AFB), PPD testing, and collagen vascular disease markers was negative.

Copyright (C) 2016, Tehran University of Medical Sciences and Iranian Society of Radiology. This is an open-access article distributed under the terms of the Creative Commons Attribution-NonCommercial 4.0 International License (http://creativecommons.org/licenses/by-nc/4.0/) which permits copy and redistribute the material just in noncommercial usages, provided the original work is properly cited. 
The patient was referred to a cardiac surgeon. After midsternotomy, the pericardium was opened. No fluid or pathologic finding was seen in the pericardium. On the right side and outside the pericardium, a huge pericardial cyst measuring approximately $13 \times 8 \times 5 \mathrm{~cm}$ in diameter was found and totally excised (Figures 3 and 4 ).

After 5 days, the patient was discharged uneventfully. Pathologic report confirmed the diagnosis. The patient remains symptom-free in the 12 month follow-up visit.

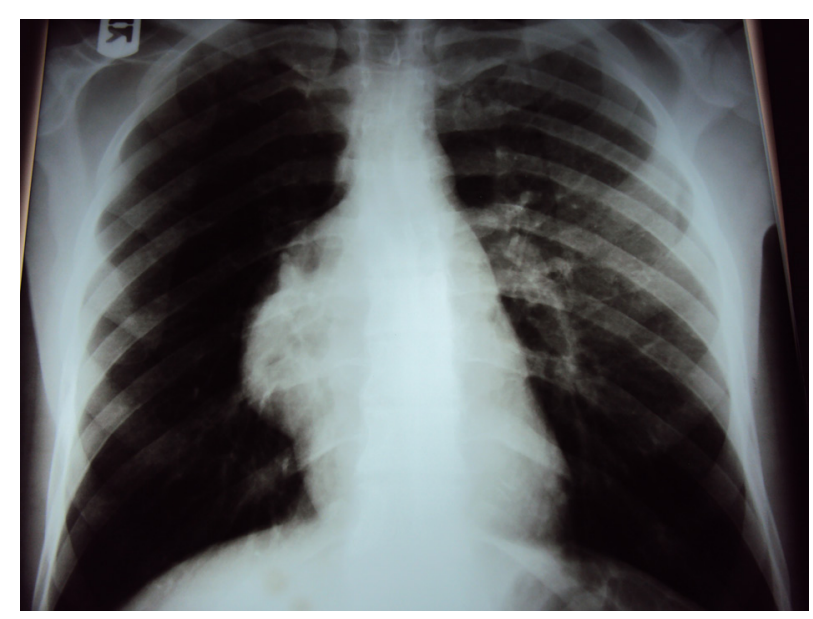

Figure 1. A 24-year-old man with dyspnea and persistent cough. Posteroanterior (PA) chest radiography revealed a well-marginated homogeneous opacity in the middle right border of the heart margin.

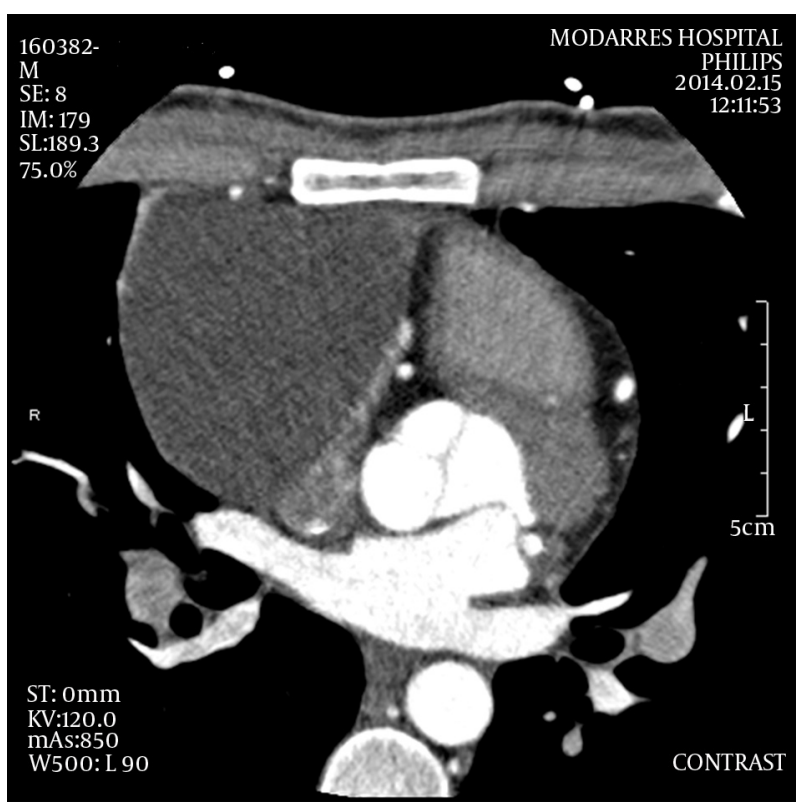

Figure 2. Axial view of patient's contrast-enhanced chest computed tomography. Mediastinal windows of thorax CT scan revealed a homogeneous cyst.

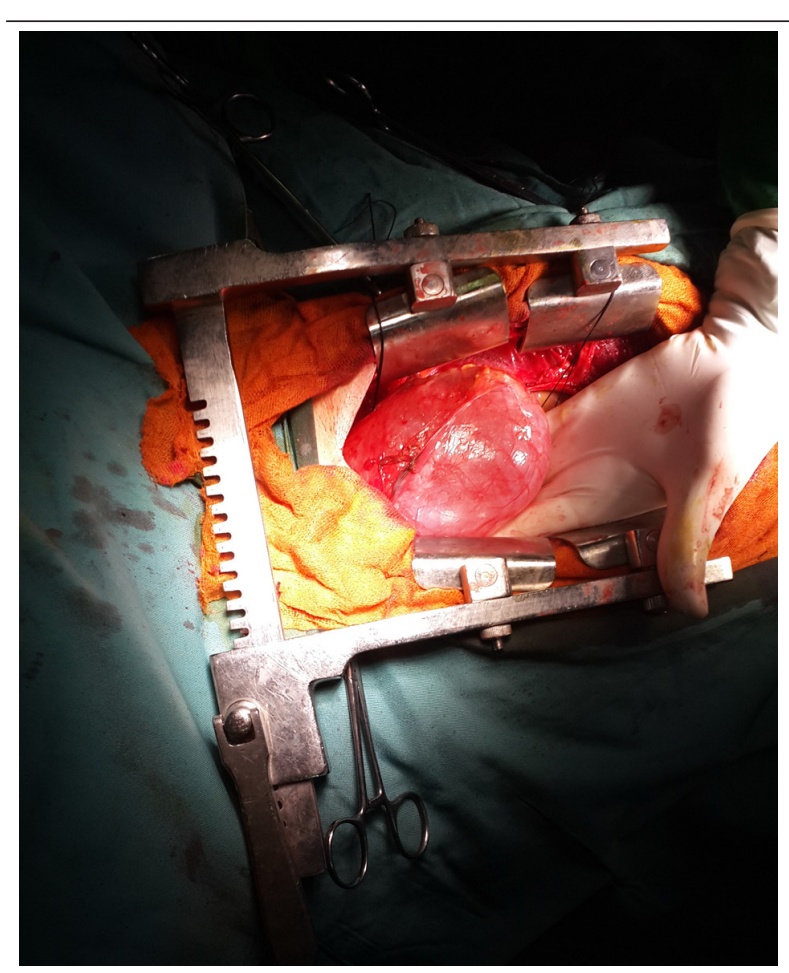

Figure 3. A thin-walled pericardial mass is seen in intra-operative photography.

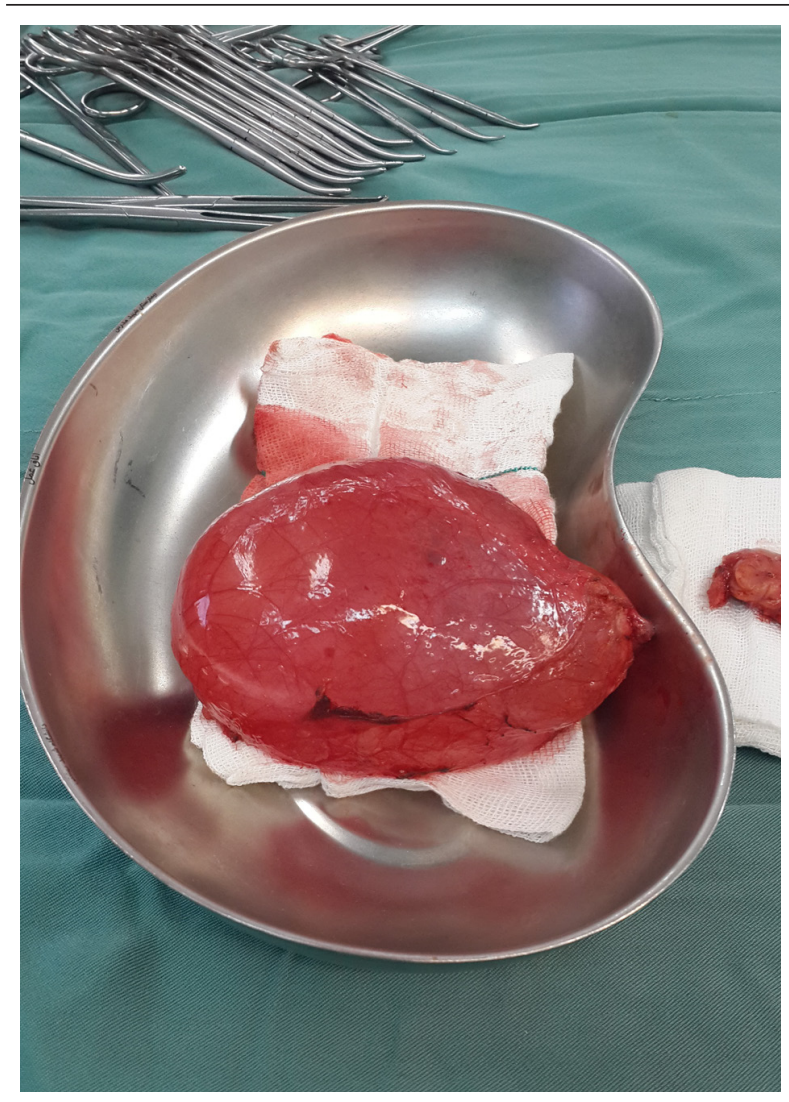

Figure 4. A completely excised huge pericardial cyst placed on the surgical sponge. Image shows an enucleated serum filled cyst. 


\section{Discussion}

The incidence of pericardial cysts is about 1 per 100,000 (1). Pericardial cysts are uncommon benign congenital lesions in the middle mediastinum $(1,4)$.

Most of the masses in the middle mediastinum (61\%) are cysts $(1,5)$. Pericardial cysts and also bronchogenic cysts are the second most common masses after lymphomas (1). Other cysts in the mediastinum are bronchogenic (34\%), enteric (12\%), thymic and others $(21 \%)(1,4)$.

Pericardial cysts (or benign mesothelial cysts), are uncommon lesions that are often found incidentally. There is no sex predilection (6). Their formation may result from failure of fusion of one of the mesenchymal lacunae that form the pericardial sac (6). On histologic examination, the cyst wall is composed of fibrous tissue lined by mesothelium, like normal pericardium, with mild chronic inflammation (6).

Most of them are asymptomatic (50\% - 75\%) and found incidentally during routine chest X-ray or echocardiography (2). Additional diagnostic methods include trans-thoracic echocardiography, CT scan and magnetic resonance im- aging (MRI). The frequency of follow up imaging has not been established yet (7). Contrast-enhanced CT scan has been the modality of choice for diagnosis and follow-up (3). On CT scan, the pericardial cyst is thin-walled, sharply defined, and an oval homogeneous mass. Their attenuation is slightly higher than water density (30 - $40 \mathrm{HU})$. Pericardial cysts do not enhance with intravenous contrast (7). Pericardial cyst calcification or rupture occurs rarely(4).

The diagnosis usually is suspected following abnormal findings on chest radiography, showing bulging of the right heart border. Additional diagnostic modalities that may find pericardial cysts include transthoracic echocardiography, CT, and MRI of the chest $(3,5,8)$.

The age distribution is not well defined. Twenty reported cases of pericardial cysts in literatures presented before the age of eighteen (1), but most of the articles reported older patients.

Pericardial cysts are usually unilocular, smooth, and smaller than $3 \mathrm{~cm}$ in diameter (5). Cyst size varies from 2 to $28 \mathrm{~cm}$ (1). In our patient, the cyst size was $13 \times 8 \times 5 \mathrm{~cm}$ in diameter that is one of the largest cysts we have found in the literature (9) (Table 1).

\begin{tabular}{|c|c|c|c|c|c|c|c|}
\hline Reference & $\begin{array}{c}\text { Publication } \\
\text { Year }\end{array}$ & Age, y & Gender & Size, $\mathrm{cm}$ & Location & Presenting Symptom & Treatment \\
\hline Present study & 2015 & 24 & Male & $13 \times 8 \times 5$ & Right side & $\begin{array}{l}\text { Dyspnea and persistent } \\
\text { cough }\end{array}$ & $\begin{array}{l}\text { Surgical excision with } \\
\text { median sternotomy }\end{array}$ \\
\hline Simsek et al.(10) & 2014 & 28 & Male & $6.4 \times 9$ & Right side & $\begin{array}{l}\text { Fever, sore throat, dry } \\
\text { cough, pleuritic chest pain }\end{array}$ & Conservative management \\
\hline Hamad et al.(11) & 2013 & 30 & Male & $11.2 \times 7.4$ & Right side & $\begin{array}{l}\text { Weight loss }(15 \mathrm{Kg}) \text {, } \\
\text { palpitation,chest pain }\end{array}$ & Surgical treatment \\
\hline $\begin{array}{l}\text { Forouzandeh et } \\
\text { al.(12) }\end{array}$ & 2012 & 71 & Female & $8 \times 5$ & Right side & Dyspnea, cough, fever & $\begin{array}{l}\text { Video-assisted thoracoscopic } \\
\text { excision }\end{array}$ \\
\hline Celik et al. (13) & 2012 & 54 & Male & $6.5 \times 4.7$ & Left side & Acute coronary symptom & $\begin{array}{c}\text { Surgical resection and } \\
\text { bypass operation(CABG) at } \\
\text { the same time }\end{array}$ \\
\hline Kaklikkaya (9) & 2011 & 39 & Male & $22 \times 15 \times 7$ & Left side & $\begin{array}{l}\text { Several episodes of left } \\
\text { pleuritic chest pain }\end{array}$ & Left side thoracotomy \\
\hline Kumar et al.(14) & 2011 & 5 & $\begin{array}{l}\text { Male } \\
\text { (child) }\end{array}$ & $10 \times 9.5 \times 9$ & Right side & Chest pain, cough, fever & $\begin{array}{l}\text { Surgical excision with } \\
\text { median sternotomy }\end{array}$ \\
\hline Thanneer et al. (15) & 2011 & 22 & Female & $\begin{array}{c}21.5 \times 11.4 \times \\
14.2\end{array}$ & $\begin{array}{l}\text { Behind the heart } \\
\text { in posterior } \\
\text { mediastinum }\end{array}$ & Syncope & Needle aspiration \\
\hline Matono et al.(16) & 2010 & 38 & Male & $12 \times 10$ & Right side & $\begin{array}{c}\text { Asymptomatic and excised } \\
\text { because of rapid growing } \\
\text { after } 20 \text { years }\end{array}$ & $\begin{array}{c}\text { Video-assisted thoracoscopic } \\
\text { excision }\end{array}$ \\
\hline Neizel et al.(17) & 2010 & 59 & Female & $\begin{array}{l}\text { Approxi- } \\
\text { mately } 5 \times 5\end{array}$ & $\begin{array}{l}\text { intrathoracic } \\
\text { mass behind the } \\
\text { heart }\end{array}$ & $\begin{array}{l}\text { Atrial flutter and } \\
\text { presyncope }\end{array}$ & Excision with surgery \\
\hline Pereira et al.(18) & 2008 & 73 & Female & $14 \times 10 \times 7$ & $\begin{array}{l}\text { Right and ante- } \\
\text { rior and left side } \\
\text { of heart }\end{array}$ & Retrosternal pain & $\begin{array}{l}\text { Referred for surgery but was } \\
\text { not operated }\end{array}$ \\
\hline Nina et al. (19) & 2007 & 44 & Female & $13 \times 9.5$ & Right side & $\begin{array}{l}\text { Progressive exertional } \\
\text { dyspnea, right side chest } \\
\text { pain, dry cough }\end{array}$ & Right side thoracotomy \\
\hline Dernellis et al. (20) & 2001 & 27 & Female & $\begin{array}{l}15.6 \times 12.2 \\
\times 5.6\end{array}$ & Right side & Asymptomatic & $\begin{array}{c}\text { Surgical removal (the reason } \\
\text { for referral for surgery was } \\
\text { not mentioned) }\end{array}$ \\
\hline
\end{tabular}


CT scan with contrast has been the diagnostic modality of choice to follow asymptomatic patients with pericardial cysts (1). However, no studies have shown the superiority of contrast CT over MRI and echocardiography for diagnosis or follow-up. On CT scan, pericardial cysts are thin-walled, sharp, oval homogeneous masses. Their attenuation is slightly higher than water density (30 to 40 HU) (2). Their enhancement with intravenous contrast is poor (2).The frequency of follow-up imaging has not been defined.

Management of pericardial cysts depends on their symptom. If the patient is asymptomatic, serial echocardiography is enough, but if the patient is symptomatic or reveals an increase in the size of the cyst or has solid component in the cyst cavity in the serial followup,a cyst resection has been the most favored approach [with thoracotomy or sternotomy or video-assisted thoracic surgery (VATS)] $(3,5)$. Aspiration is another method, but one-third of the patients have shown recurrence.

Non-operative strategy may be selected for high-risk patients. The longest reported follow-up lasted twenty five years. Cyst aspiration is another therapeutic option. One literature review reported that about $30 \%$ of the patients had recurrence after percutaneous drainage at three years. Sclerosis has been reported to decrease recurrence rate after aspiration (5).

Morbidity and mortality are low. Surgery has been demonstrated as the only definitive curative treatment (1).

\section{Authors' Contributions}

All authors contributed extensively to the work presented in this paper. Seyedeh Adeleh Mirjafari was the corresponding author and helped in all aspects. Abbas Arjmand Shabestari contributed to the radiologic findings. Manouchehr Hekmat, Hassan Tatari, and Hamid Ghaderi were the surgeons. Hamid Ghaderi prepared the case and helped in the discussion part. All authors contributed to the writing of the manuscript. All authors read and approved the final manuscript.

\section{References}

1. Komanapalli P, Sukumar M. Pericardial Cyst. 2014. Available from: http://www.ctsnet.org/sections/clinicalresources/clinicalcases/ article-16.

2. Demos TC, Budorick NE, Posniak HV. Benign Mediastinal Cysts. J Comput Assist Tomo. 1989;13(1):132-3.

3. Najib MQ, Chaliki HP, Raizada A, Ganji JL, Panse PM, Click RL. Symptomatic pericardial cyst: a case series. Eur J Echocardiogr 2011;12(11):E43.

4. Islas F, de Agustin JA, Gomez de Diego JJ, Olmos C, Ferrera C, Luaces $\mathrm{M}$, et al. Giant pericardial cyst compressing the heart. J Am Coll Cardiol. 2013;62(10):e19.

5. Cohn LH. Cardiac Surgery in the Adult, 4e. McGraw-Hill Professional; 2012.

6. Allen P, Burke FT. Practical Cardiovascular Pathology. Lippincott Williams \& Wilkins; 2011.

7. Frisoli T, Grosu H, Paul S, Eden E. Recurrent Rupture of a Pericardial Cyst Presenting as Syncope, Pleuropericarditis, and Pneumonitis. Chest J. 2011;140(4):90A.

8. Comoglio C, Sansone F, Delsedime L, Campanella A, Ceresa F, Rinaldi M. Mesothelial cyst of the pericardium, absent on earlier computed tomography. Tex Heart Inst J. 2010;37(3):354-7.

9. Kaklikkaya I. A giant pericardial cyst. Cardiovasc J Afr. 2011;22(6):e1-3.

10. Simsek H, Gunes Y, Akil MA, Bilsel T. Asymptomatic giant pericardial cyst mimicking dextrocardia on chest X-ray. Herz. 2014;39(8):1013-5.

11. Hamad HM, Galrinho A, Abreu J, Valente B, Bakero L, Ferreira RC Giant pericardial cyst mimicking dextrocardia on chest X-ray. Rev Port Cardiol. 2013;32(1):49-52.

12. Forouzandeh F, Krim SR, Bhatt R, Abboud LN, Ramchandani M Chang SM. Giant pericardial cyst presenting as pneumonia. Tex Heart Inst J. 2012;39(2):296-7.

13. Celik T, Firtina S, Bugan B, Sahin MA, Ors F, Iyisoy A. A giant pericardial cyst in an unusual localization. Cardiol J. 2012;19(3):317-9.

14. Kumar S, Jain P, Sen R, Rattan K, Agarwal R, Garg S. Giant pericardial cyst in a 5-year-old child: A rare anomaly. Ann Pediatr Cardiol. 2011;4(1):68-70.

15. Thanneer L, Saric M, Perk G, Mason D, Kronzon I. A giant pericardial cyst. J Am Coll Cardiol. 2011;57(17):1784.

16. Matono R, Shoji F, Yano T, Maehara Y. Surgical resection of a giant pericardial cyst showing a rapidly growing feature. Interact Cardiovasc Thorac Surg. 2010;10(6):1056-8.

17. Neizel M, Kruger S, Spillner J, Kelm M, Kuhl HP. A giant pericardial cyst as unusual cause for atrial flutter. J Am Coll Cardiol. 2010;55(11):1160.

18. Pereira A, Tavares NJ, Thomas B. Magnetic resonance imaging of a giant pericardial cyst. Rev Port Cardiol. 2008;27(4):547-8.

19. Nina VJ, Manzano NC, Mendes VG, Salgado Filho N. Giant pericardial cyst: case report. Rev Bras Cir Cardiovasc. 2007;22(3):349-51.

20. Dernellis J, Theodosiou P, Fois L. An asymptomatic giant pericardial cyst. Int J Cardiol. 2001;2(78):185-7. 